\title{
Now Tell Us What You Want: Information Seeking Habits of Health Sciences Faculty
}

\author{
Megan Inman
}

Amy E. Blevins

Elizabeth Ketterman

Kristen Young

\section{Keywords}

information seeking, electronic resources, library services, survey

\section{Authors}

Megan Inman, MLIS, inmanm@ecu.edu , Collection Development Librarian

East Carolina University, William E. Laupus Health Sciences Library, 600 Moye Blvd, Greenville NC 27834

Amy E. Blevins, Indiana University, Ruth Lilly Medical Library

Elizabeth Ketterman, East Carolina University, William E. Laupus Health Sciences Library

Kristen Young, Department of Veterans Affairs, Cincinnati, Ohio

\section{ABSTRACT}

Over the years, library collections have vastly changed due to an ever-growing presence of resources available online. Many libraries have experienced a dramatic decrease in the circulation of physical materials with the shift to online availability of materials. It is of great value to ensure that libraries are meeting the needs of their users and this can be accomplished by identifying their information seeking patterns. The aim of this article is to examine how faculty use the library and to identify what services and resources are of value to their work. 


\section{INTRODUCTION}

For over a decade, librarians have been examining the effect of online resources on user behavior. ${ }^{1}$ The nature of library collections has greatly changed in recent history with more and more resources available online. Many libraries have seen a dramatic drop in the circulation of physical materials as libraries have transitioned to electronic materials. In addition, libraries have seen a drop in reference transactions. ${ }^{2}$ The decrease in reference transactions may suggest that users are able to find the answers to many of their questions using online resources and search engines without the aid of librarians. Librarians are eager to ensure that they are meeting the needs of their users, and one way to do this is by understanding the information seeking patterns of health sciences library users.

Several studies have been done to examine the information seeking habits of different library user populations, with some focusing specifically on health sciences populations..$^{3-6}$ Rupp-Serrano and Robbins ${ }^{4}$ conducted a series of studies examining the information-seeking habits of faculty in several disciplines at over twenty large institutions using Robbins, Engel, and Kulp as a model. ${ }^{9}$ One of the goals was to look at the "generalizability of findings of single institution studies." 4 This article focuses on education faculty and contains a lengthy literature review devoted to the information seeking patterns of social sciences faculty and suggests a shift over time from relying on colleagues and journal literature to a mixture of books and journal literature and on to a reliance on electronic databases and resources. They found that $98 \%$ of respondents ranked electronic access to journals as important. While this study did not include health sciences faculty members, it is worth mentioning because of two things: the attempt to 
generalize single studies to larger populations, and that it looks at faculty members at institutions of higher education.

With regards to the health sciences: Connor's study looked at the information seeking habits of health consumers, ${ }^{5}$ Duncan and Holtslander looked at the information seeking habits of nursing students, ${ }^{6}$ and Gilman looked at the information seeking habits of recent graduates from an occupational therapy program. ${ }^{7}$ A study done at the University of Illinois at Chicago in 2011 specifically focused on online resources and health sciences faculty. This was a continuation of a study that was done in 2003 , using a modified version of a survey used for a study in $2000 .^{8}$ Their goal was to determine the effects that changes in online resources (including social media, expanding options for point-of-care tools, and ubiquity of handheld devices) may have had on information seeking behaviors. Their study concluded that faculty members used MEDLINE, Google, and Google Scholar on a regular basis. A large number of respondents stated that they had never used many of the other databases listed in the survey. The primary reasons for using databases were research $(90.8 \%)$, keeping current (63.8\%), preparing instruction $(57.7 \%)$, and patient care $(37.2 \%) .^{3}$

\section{BACKGROUND}

The William E. Laupus Health Sciences Library is a part of East Carolina University's (ECU's) Division of Health Sciences and is charged with the mission of providing access to quality health information in support of education, research, and clinical care in eastern North Carolina. It is an academic health sciences library serving the College of Allied Health Sciences, College of 
Nursing, School of Medicine, and School of Dental Medicine. The combined enrollment for these schools was 1,720 students as of the 2014-2015 academic year. ${ }^{10}$

\section{METHODOLOGY}

While the study undertaken at this institution was similar in some ways to the one done in Chicago, ${ }^{3}$ there are some differences. The study conducted in Chicago had a heavy focus on specific online resources and specific uses like patient care, research, and staying current. This

study was modeled after Rupp-Serrano and Robbins, ${ }^{4}$ with their permission, and looks at a wider breadth of reasons for utilizing library resources. The aim of this research study is to examine how faculty use the library and to identify what services and resources are of value to their work.

For this study the authors surveyed health science faculty members affiliated with the university. Faculty were selected to be the primary population surveyed for the study because the authors were interested in reviewing their information seeking habits. Prior to initiating the study, exempt status from the institutional review board was obtained. The 15 -item survey was designed to be concise, comprehensive and completed in as little as 10 minutes. Qualtrics, a web-based software, used to create surveys, evaluations, and generate reports was used for the online survey platform. ${ }^{11}$

An invitation for voluntary participation in the survey was sent out via e-mail in February 2016 to approximately 1,063 health sciences faculty affiliated with the university. All e-mail addresses for health sciences faculty were gathered from the university's website by the authors of this research paper and the list included full, associate, assistant and adjunct professors, clinical instructors and professor emeritus instructors and professional staff that hold professorial rank. Faculty were given two weeks to respond and a reminder was sent via e-mail. The survey 
Information Seeking Habits

used was adapted, with permission, from the 2013 article titled Information-Seeking Habits of Education Faculty by Rupp-Serrano and Robbins in College \& Research Libraries. ${ }^{4}$ Changes made to the Rupp-Serrano survey were minimal and included editing survey selections to reflect the patrons of health sciences libraries.

The topics covered by the questions included the frequency that information is accessed to complete tasks; importance of journals, internet resources, and consultations in research; keeping abreast of updates in the field; importance of library assistance and services; factors that influence, improve and limit the use of information sources and services; and the respondent's primary status, field of expertise, length of time in their area of study, and departmental duty within the university. The full survey is provided in Appendix 1. Quantitative data was gathered to better assist the authors to better understand the information seeking traits of health sciences faculty in regard to the use of library materials and resources at the Library. The survey responses were both anonymous and confidential. Participants were not required to answer every question, could stop at any time and had the ability to save the survey and return to it later.

\section{RESULTS}

Of the health sciences faculty contacted, $114(10 \%)$ completed the survey and were included in this study. As indicated in Table 1. Demographics, the response population consisted of $32 \%$ full professors, 29\% associate professors, 23\% assistant professors, $14 \%$ clinical instructors, $2 \%$ adjunct professors, $1 \%$ instructor professor emeritus, $1 \%$ staff. The majority of respondents reported working in their area of study for 16 years or longer (46\%), following this $0-5$ years (21\%), then 6-10 years (18\%), and finally $11-15$ years $(15 \%)$. 
Table 1. Demographics.

\begin{tabular}{lr}
\hline University Status & \\
Professor & $32 \%$ \\
Associate Professor & $29 \%$ \\
Assistant Professor & $23 \%$ \\
Adjunct Professor & $2 \%$ \\
Clinical Instructor/professor & $14 \%$ \\
Instructor Professor Emeritus & $1 \%$ \\
Staff & $1 \%$ \\
Length of Time in Field & \\
$0-5$ years & $21 \%$ \\
$6-10$ years & $18 \%$ \\
$11-15$ years & $15 \%$ \\
$16+$ years & $46 \%$ \\
Primary Field of Expertise & \\
Allied Health & $30 \%$ \\
Dentistry & $9 \%$ \\
Medicine & $41 \%$ \\
Nursing & $17 \%$ \\
Pharmacy & $1 \%$ \\
Public Health & $3 \%$ \\
\hline
\end{tabular}

Table 1: Demographics

The most commonly selected fields of expertise were medicine (41\%) and allied health $(30 \%)$. Then as follows: nursing (17\%), dentistry (9\%), public health $(3 \%)$, and pharmacy $(1 \%)$. Instruction was shown as a common departmental duty: graduate instruction (72\%), professional student instruction (53\%), undergraduate instruction (43\%), and resident instruction (44\%). Administrative duties (48\%), grant preparation (45\%), field/laboratory research (41\%), and clinical/patient care (42\%) were also frequently reported obligations.

In the last five years, respondents of the survey most frequently produced conference presentations, conference posters, peer reviewed journal articles and book chapters. Conference proceedings, books, and patents/commercial projects were the least produced items. 


\section{Frequency of Seeking Information}

The individuals surveyed were asked to indicate the frequency of seeking information based on a myriad of tasks, as shown in Figure 1. These tasks included preparing for student lectures, conference presentation preparation, writing/research for publication, preparing a new research proposal/grant application, professional development/remain current in the field, and making decisions regarding patient care. Seeking information for professional development and to help remain current in the field was the highest daily task reported (35\%). Respondents indicated that on a weekly basis information was accessed for preparing for student lectures $(42 \%)$ and publication research $(30 \%)$. Preparation of conference presentations new research proposals were reported most frequently on a monthly basis or less often.

\section{How frequently do you seek/and or access information to} complete the following tasks?

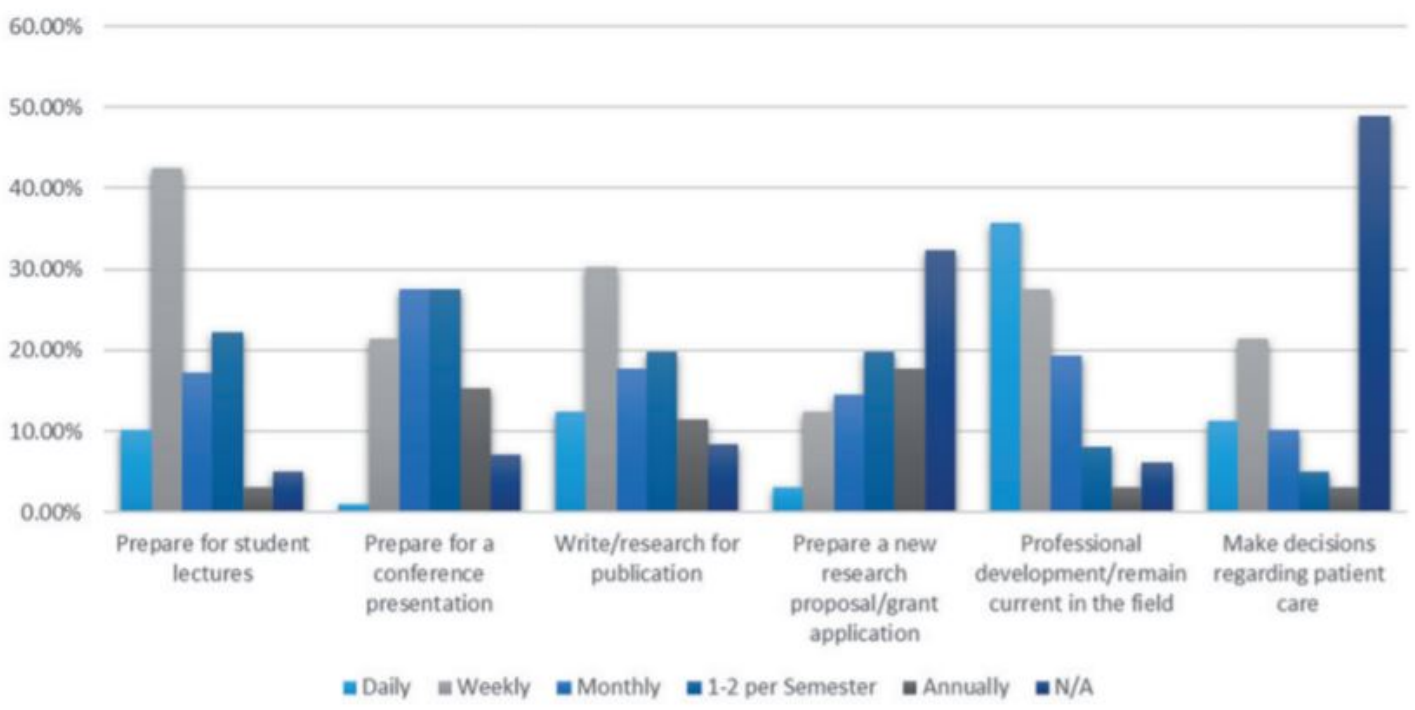

Figure 1: Frequency of accessing information 
Respondents indicated that they stayed current most often by scanning current issues of journals (92\%), attending conferences $(86 \%)$, or by following leads or references from an article or an item of interest (85\%). Other ways of staying up to date in the field include personal communications (61\%), email alert services (36\%), and electronic discussion lists (24\%).

When asked what factors influence their use of information, authoritativeness (85\%), availability (83\%), and ease of use (81\%) were most frequently selected. Other criteria selected were currency (68\%) and familiarity $(39 \%)$.

\section{Value of library services and resources for faculty members}

The majority of respondents (75\%) indicated that the library was very important to conducting research in their field of health sciences. Following this, survey respondents noted the use of the library in their research as important (19\%), and 5\% were neutral.

Respondents were asked how important seven resource item types were in their research, as indicated in Figure 2. Scholarly journals (print or online) were considered extremely important (87\%) as were internet resources (69\%). Resources considered very important were as follows: attendance at conferences (44\%), books (41\%), email/face to face discussion with colleagues (41\%), and email/face to face discussion with students $(35 \%)$. 


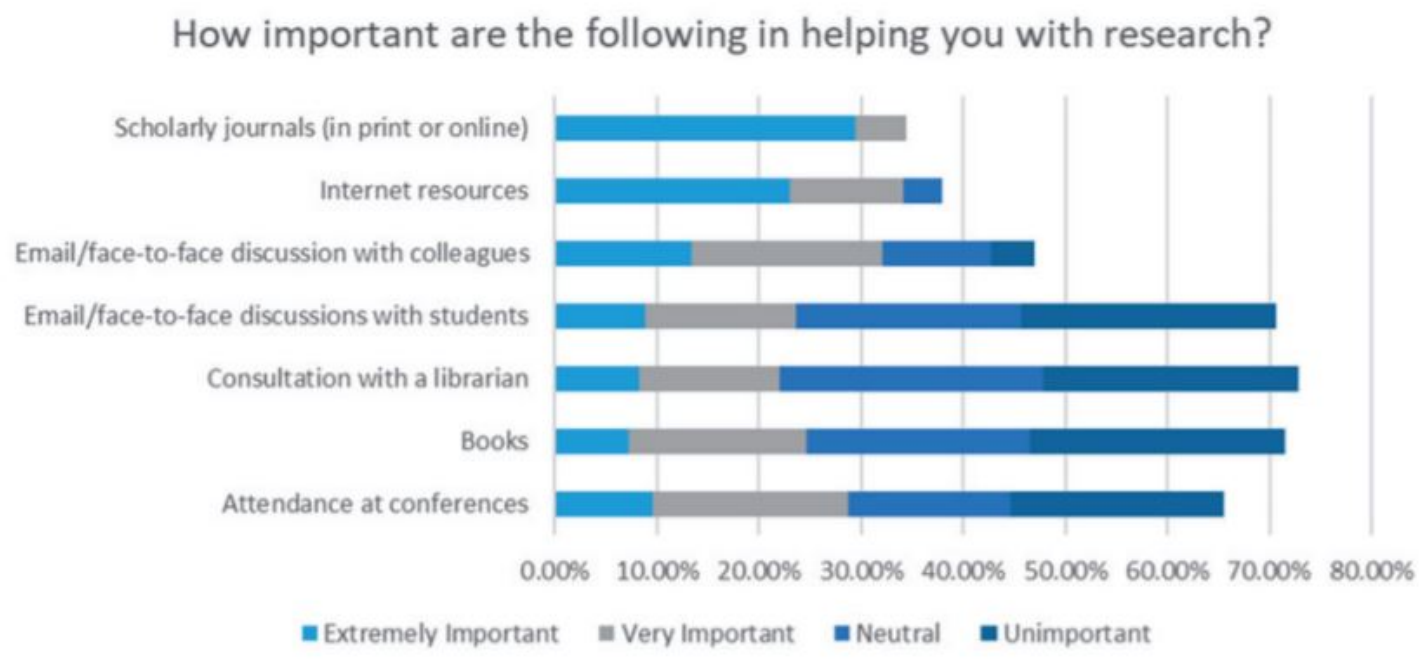

Figure 2: Value of library services and resources

Figure 3 summarizes the importance of ten different library services in meeting users' information needs. Electronic access to current journals was indicated as very important by $92 \%$ of those surveyed. Other items ranked as very important include library databases such as PubMed (88\%) and electronic access to archives of library journals (88\%). Regarding print journal subscriptions, the most common answer was neutral (37\%). In contrast, only $36 \%$ felt the print book collection was important and 34\% were neutral. Survey respondents indicated that the electronic book collection was very important $(36 \%)$ or important $(45 \%)$. Also indicated as very important $(37 \%)$ or $(38 \%)$ important was interlibrary loan/document delivery. Faculty felt that assistance from library personnel was very important (40\%) or important (35\%). Respondents were neutral (51\%) in regard to library workshops and the library as a space to study/conduct research (34\%). 


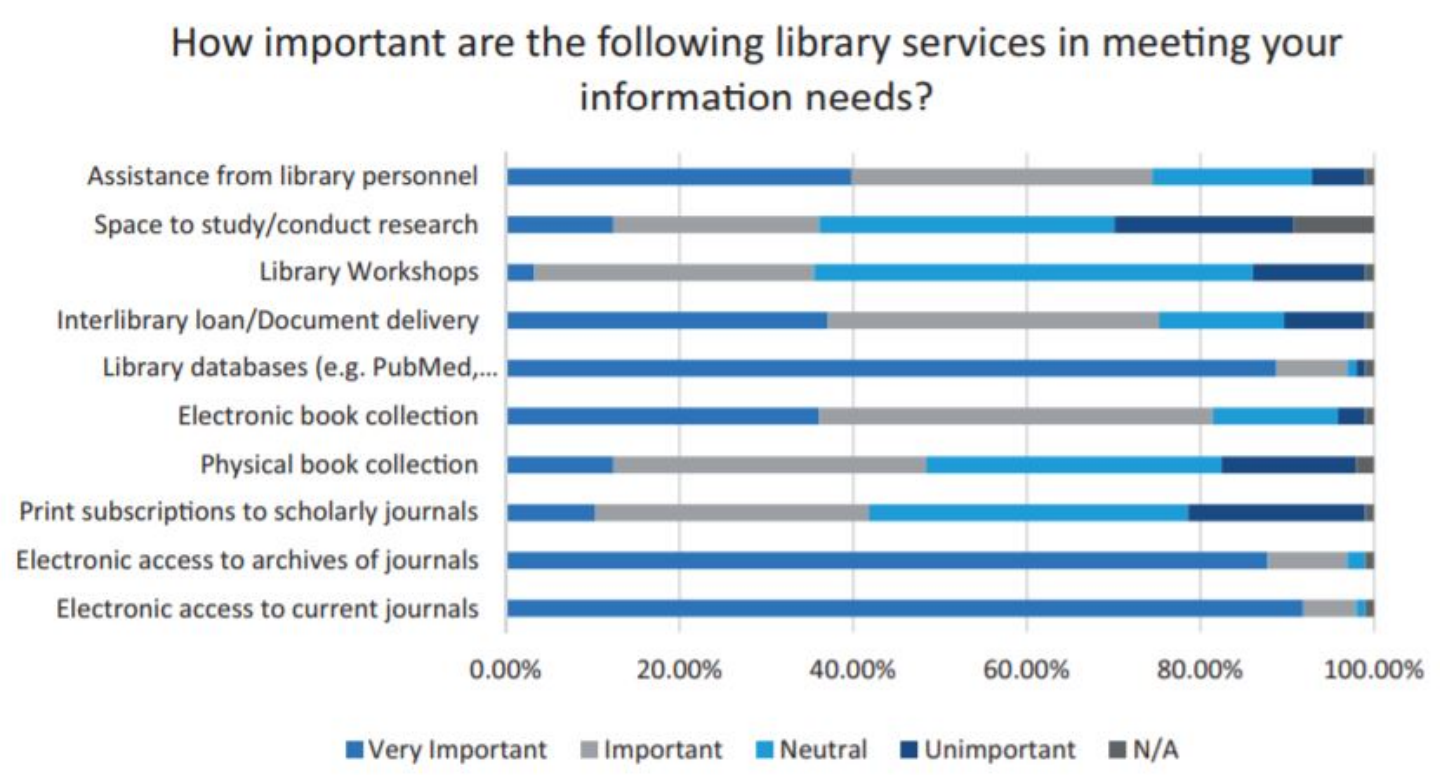

Figure 3: Importance of library services in meeting information needs

When receiving assistance with library resources, respondents indicated that one on one consultations with library personnel are very important (43\%). The majority were neutral in regard to library workshops, classes, or presentations (43\%). Of those surveyed, $50 \%$ felt that helpsheets/tutorials are important and $17 \%$ indicated that they are very important.

As illustrated in Figure 4, lack of time (53\%) and the unavailability of needed electronic resources (52\%) are indicated most frequently when questioned about what factors might limit their use of library electronic services and resources. Other factors were unawareness of the resources $(38 \%)$, that resources are hard to find on the library website $(26 \%)$, and a lack of instruction (20\%). 


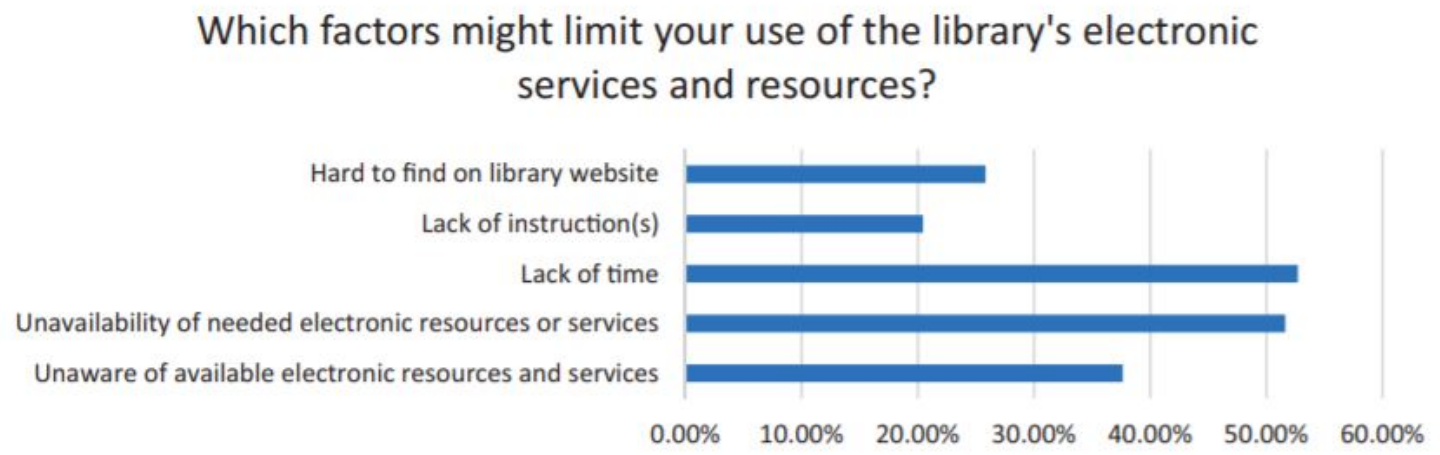

Figure 4: Limiting factors

Faculty were asked how the library's electronic resources and services improve finding needed information. Most of those surveyed (94\%) indicated that access to electronic resources allows working from office or home and that it speeds up their research process $(90 \%)$. Also frequently indicated, was that the library helps to provide access to full text publications $(86 \%)$. Sixty two percent of respondents said that the library? helps them to assist students in their research efforts more effectively.

\section{DISCUSSION AND CONCLUSION}

The results from this survey provide some insights into health sciences information seeking behavior at the local level that correlate with broader trends mentioned in the introduction, including why there is decreasing use of physical materials, why there is an increase in electronic materials, and why health sciences researchers use what they use.

Two important results from the survey are: 1 . books are a less valued source of information than journals (similar to results found by Rupp-Serrano and Robbins ${ }^{4}$ ), and 2. online resources are more valued than books. The proportion of a library's budget dedicated to 
electronic journal purchasing could be analyzed to support this identified patron preference. It may be useful to explore in the future if there are differences in faculty and student opinions regarding electronic books and electronic book platforms. At present, a subset of this study's authors are conducting a study evaluating expenditures and use of resources in book format.

Scanning current journal literature is still the most regularly utilized method for staying current in the respondents' fields. The ability to retrieve that information easily is as important as its authoritativeness. Further study into the authoritativeness would yield important results for libraries. It would be beneficial to know what is the tipping point in the balance between authority and easy procurement of information, and use that information to determine how to make it easier for faculty to retrieve authoritative articles.

As for service, one of the noteworthy results is that one-on-one assistance from librarians is considered very important while the same number of respondents were neutral about library instruction classes. This result could imply that librarians should invest more time and effort on developing skills and resources to support one-on-one assistance than on course preparation.

A surprise in the results is that a majority of respondents indicated that unavailability of information resources limits their library use. When considering this with the response that almost $30 \%$ of respondents indicated information is hard to find on the website, there is a possibility that the information is available but too hard to find. The library should engage in usability testing to determine if pathway changes could make the library catalog? more findable.

In addition to surveying students and their space seeking habits, future plans include reworking this survey so that it could be administered at multiple institutions, and repeating a survey of faculty every five or ten years. Further examination of expenditure and collection use 
data would also be of benefit. This would aid in the allocation of funds in areas within collection development.

\section{REFERENCES}

1. D’Alessandro, Michael P, Donna M D’Alessandro, Jeffrey R Galvin, and William E Erkonen. "Evaluating Overall Usage of a Digital Health Sciences Library,” Bulletin of the Medical Library Association 86, no. 4 (October 1998): 602-9.

2. Association of Academic Health Sciences Libraries. "Annual Statistics of Medical School Libraries in the United States and Canada, 2008-2015.” Accessed January 18, 2018.

3. De Groote, Sandra L, Mary Shultz, and Deborah D Blecic. "Information-Seeking Behavior and the Use of Online Resources: A Snapshot of Current Health Sciences Faculty," Journal of the Medical Library Association 102, no. 3 (July 2014): 169-76

4. Rupp-Serrano, Karen, and Sarah Robbins. "Information-Seeking Habits of Education Faculty," College and Research Libraries 74, no. 2 (March 2013): 131-41.

5. Connor, Elizabeth. "Taking the Pulse of Health Information Seeking," Journal of Electronic Resources in Medical Libraries 6, no. 3 (July 2009): 230-35.

6. Duncan, Vicky, and Lorraine Holtslander. "Utilizing Grounded Theory to Explore the Information-Seeking Behavior of Senior Nursing Students," Journal of the Medical Library Association 100, no. 1 (January 2012): 20-27. 
7. Gilman, Isaac P. “Evidence-Based Information-Seeking Behaviors of Occupational Therapists: A Survey of Recent Graduates," Journal of the Medical Library Association 99, no. 4 (October 2011): 307-10.

8. De Groote, Sandra L, and Josephine L Dorsch. "Measuring Use Patterns of Online Journals and Databases," Journal of the Medical Library Association 91, no. 2 (April 2003): 23140.

9. Robbins, Sarah, Debra Engel, and Christina Kulp. "How Unique Are Our Users? Comparing Responses Regarding the Information-Seeking Habits of Engineering Faculty," College and Research Libraries 72, no. 6 (November 2011): 515-32.

10. East Carolina University's Office of Institutional Planning, Research, and Effectiveness. Fact Book 2014-2015. Accessed January 18, 2019. https://performance.ecu.edu/portal/?itemId=91d270c1-bad4-e511-95c6-005056890024

11. Qualtrics. Qualtrics 2005. 2018. Provo, Utah, USA. Version available at https://qualtrics.com 